\title{
LOMPATAN KEMAJUAN UII DALAM USIA KE-70
}

\author{
Darwin Harsono \\ Fakultas Hukum Universitas Islam Indonesia
}

\begin{abstract}
The historical background of Indonesian Islamic University is very phenomenal thing especially for mapping of progress of Indonesia as afree country. Some of the founding of UII are the leaders of the Republic of Indonesia. They 're the true statesmen who aimed to accelerate the development of the nation through education and politics. Than they iniciated to build an Islamic University (IIU) in accordance with the need of muslim' country especially and for the nation in general. IIU's vision and mission shows up the goal of it and of course it's Islam to be assured of making Islamic system of education based on Qur'an's message namely 'rahmatan Iil'alamin - benevolence for Universe (Q 21: 107). It will gives guaranty in the long run good out put : high dedicated and integrated alumnies for glorifieng Islam and muslim's people. For now on it's the duty of IIU for preparing hard ware and soft ware taking a high role as a center of excellence, of IIU in ASEAN, sublimized the loss glory of Andalusian' Islamic University.
\end{abstract}

Key words: IIU, Indonesia, vision, mission.

\section{PENDAHULUAN}

Berangkat dari pendirian institusi pendidikan dengan nama Sekolah tinggi Islam, kemudian Universiteit Islam Indonesia dan pada akhirnya menjelma menjadi Universitas Islam Indonesia, bukanlah hal yang sederhana. Para pendiri UII meletakkan fondasi bangunan Balai pendidikan Tinggi dengan semangat keilmuan yang bertumpu pada nilai-nilai ajaran Islam.

UII di satu sisi didirikan untuk mengejar kemajuan bagi masyarakat muslim Indonesia. Yudi Latif, seorang cendikiawan muda muslim, menambahkan bahwa UII kedudukannya menjadi teramat penting sebagai universitas swasta Islam pertama, yang menawarkan fakultas-fakultas umum dan agama.Terlebih lagi universitas ini menjadi pusat pertumbuhan dan perkaderan awal bagi para pemimpin masa depan intelegensia Muslim. (Yudi Latif, 2005: 370 )

Sebuah universitas Islam yang keiahirannya memang ditunggu-tunggu dan dititipkan padanya sebuah asa yang dapat memandu umat mengisi kemerdekaan RI. Bukankah hal itu pula yang didambakan oleh presiden pertama RI, dapat menghasilkan sumber daya manusia Indonesia (SDM ) yang mengangkat Indonesia berjaya di tengah-tengah bangsa lain.

Sebuah universitas Islam yang awalnya tidak dikenal, merangkak bagai bayi yang harus dltumbuh kembangkan dengan belaian kasih sayang, dengan iman dan ghirah perjuangan umat. UII tak pernah sepi dari tantangan dan rintangan yang nyaris menenggelamkan dirinya. Umat sendiri belum banyak tahu tentang keniscayaan kehadiran pendidikan yang tertua ini.

Sebuah noktah yang bernama Universitas Islam Indonesia seakan tenggelam, tak nampak di tengah 17.000 pulau besar kecil di tengah persada nusantara, Indonesia. Betapa sulitnya menjelmakan sebuah gagasan luhur dalam bidang pendidikan, apa pula pendidikan tinggi. Ibarat manusia pun kehadirannya tak mudah, dari tiada dan berproses menjadi ada (being). Allah SWT telah mengingatkan hal ini : 


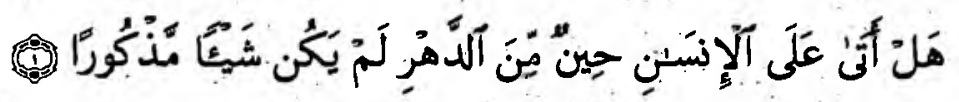

Bukankah telah datang atas manusia satu waktu dari masa, sedang Dia ketika itu belum merupakan sesuatu yang dapat disebut? QS. Al-Insan 76: 1

Quraish Shihab memetik komentar Sayyid Quthub tentang surat ( 76 ) di atas sebagai tanda ( 1 ) ajakan yang sangat lembut untuk berbakti kepada Allah, ( 2 ) berlindung kepadaNya, ( 3 ) memohon ridha-Nya, ( 4 ) mengingat nikmat-Nya, ( 5 ) menghindari siksa-Nya, ( 6 ) serta waspada terhadap cobaan-Nya.2 Patutlah keenam hal ini menjadi substansi kesyukuran buat kado milad oleh segenap civitas akademikanya. . ( Quraish Shihab, 2009:560 ).

Keberadaan UII sebagai lembaga pendidikan tinggi Islam dalam usianya ke-70 tidák diragukan. Namun ada sebuah pertanyaan tersembul, adakah ia berhasil atau sebaliknya semakin terasa memudarnya misi yang diembannya. Patut direnungkan puisi dari Jalaludin Rumi untuk rangka mengaca diri:

Selama tujuh puluh tahun penuh

Di sini aku durhaka-

Namun, tidak Dikau tahan

Karunia-Mu sehari pun!

Kini aku tidak dapat cari uang;

Aku sudah tua, aku tamu-Mu

Akan kumainkan harpa untuk-Mu

Sebab aku ini milik-Mu (Mahfud MD, 1997: 95)

Tak dapat tidak, universitas ini harus melakukan muhasabah ( otokritik ) agar jangan sampai terjebak dalam tempat yang rapuh dan keadaan yang gamang serta jangan kehilangan peluang untuk membukakan diri sebagai universitas terbaik di kelasnya. Yakni universitas Islam yang solid dalam komitmen sistem pendidikan islam.

Usia ke 70 dari sejarah UII menuntut pendukungnya menemukan elan vitalnya untuk terus bergerak maju melakukan 'sebuah lompatan kemajuan' (a leap of progress) dengan penuh nuansa kearifan, hikmah, dan mengangkat tinggi-4 sifat kenabian yaitu, kejujuran (sidik), amanah (trust) , fathonah ( smart), tabligh ( penyemai ilmu, amal,dan cita ).

\section{VISI DAN MISI UII}

Universitas Islam Indonesia dianggap konsisten sebagai institusi pendidikan tinggi Islam. la ikut secara nyata dalam penyelenggaraan kemajuan dan pencerdasan bangsa. Sedang para alumninya bertebaran di seluruh Indonesia, mengamalkan ilmu mereka dan menjadi pelaku proses perubahan, peningkatan kearah pembaharuan kehịupan yang baik atau lebih baik yang penuh kemaslahatan.

Pernah UII merefleksikan kepemimpinan ( rektorium ) seorang ulama semacam syekh Al-Azhar University Kairo seketika Syekh M. Abduh memulai pembaharuannya di bidang pendidikan Islam guna mencerdaskan umat.

Kepemimpinan berestafeta dan dipegang seorang rektor dengan kekuatan akal murni yang dibungkus dalam kebersahajaan, kepribadian yang utuh dan nilai Islam dalam praktek keilmuan. Rangkaian kepemimpinan sejak awal sampai 2013 ini telah memberikan corak dan warna UII kini.

Thesis kekuatan UII tetap eksis / berada, tentu antara lain tercermin pada hasrat para pemimpin mengambil peran murabi, memikul amanah dan berkarya ilmiah di barengi dengan empati ( al i'tinaq ) yang kuat untuk Islam dan umat muslim. Thesis lain adalah kontribusi para 
tokoh Islam bersinergi membesarkan universitas ini.

Di samping UII menolong dirinya sendiri dalam internal dinamisasi kerja keilmuan, dan managemen serta tumpuan pengalaman untuk berbagi ( sharing ) bagi kemajuannya. Thesis utama adalah pertolongan dan rahmat Allah SWT yang menjadikan UII tetap solid dalam kesatuan sebagai institusi Islam.

Para lulusan UII memiliki kesediaaan untuk memikul amanat ilmu yang harus diamalkan yang menjadi daya tarik kepercayaan umat meningkat. Bukan tidak mustahil ada kelemahan dan kekurangan universitas yang tanpa crisis center pun ia teratasi. Mengapa demikian? Hal ini harus dilacak dari pengamalan ilmu yang sifatnya kebenaran dan Islam yang bermuara pada Al Haq ( Yang Maha Benar ). Keduanya memberi petunjuk menuju jalan yang benar lagi selamat. Belajar dari rahasia pesan yang diberikan Nabi Muhammad SAW yang telah bersabda:

"Barangsiapa yang ditanya tentang sesuatu kemudian ia menyembunyikannya, maka pada hari kiamat ia akan dikekang dengan tali kekang yang berasal dari neraka." HR. Tirmidzi.

Para pendiri UII (the faunding fathers) menyiapkan pendidikan tinggi ini sebagai jembatan yang kokoh memikul tugas keilmuan, mendidik umat menguasai ilmu dan berkemampuan untuk hidup mandiri dalam kerja profesional yang penuh amal salih, baik salih individual maupun salih sosial. Mereka telah meresapi ilmu dari alma mater (ibu susu) dan mampu mempergunakan ilmunya untuk kemaslahatan umat Islam ,khususnya, bangsa dan manusia pada umumnya.

Senyampang dengan itu para pendiri UII tidak ketinggalan bergulat dalam perjuangan mengisi kemerdekaan menuju bangsa yang besar. Mereka menebarkan ilmu dalam bingkai semangat pembebasan kebodohan umat, berjuang dalam perspektif mu'allim menggapai cita masa depan yang gemilang serta, mengobarkan tekad kesatuan dan persatuan.

Ketika ibu kota RI di Yogya dibangun masjid Syuhada' dan PTI, melandasi awal kemerdekaan. Pada saat ibu kota RI berpindah ke Jakarta disertai pendirian masjid Istiqlal, Tinggallah UII yang menjadikan Yogya kota pendidikan dan kebudayaan, pusat kearifan, dan keunggulan (center of excellence).

Dirumuskanlah visi UII yang amat piawai, menggaungkan jati dirinya: Terwujudnya Universitas Islam Indonesia sebagai rahmatan lil'alamin, memiliki komitmen pada kesempurnaan ( keunggulan ), risalah islamiyah, di bidang pendidikan, penelitian, pengabdian masyarakat dan dakwah, setingkat yang berkualitas di negara-negara maju. (Agenda UII, 2013:)

Apa yang menjadi kata kunci dalam visi tersebut adalah 'terwujudnya Universitas Islam Indonesia sebagai rahmatan lil'alamin.' Kata rahmatan lil'alamin dapat ditelusuri dan ditemukan dalam Al-Qur'an (QS.Al-Ambiya'21: 107). Dengan kata lain rahmatan lil'alamin adalah bahasa dan pesan wahyu yang mengandung kemu'jizatan. Karena itu Islam dalam bahasa perjuangan ( terwujudnya termaksud ) meniscayakan Islam sebagai 'Islam ya'lu wa laa yu'la 'alaihi- Islam yang tinggi dan tak terungguli.

Ciri keistimewaan UII adalah sebuah institusi pendidikan -kerahmatan bagi alam semesta. Tuhan adalah muara dan sumber segala ilmu, Dia adalah Dzat Yang Maha Tahu ( Al-'alim ). Di sisi Allah tiada yang tidak diketahui atau tersembunyi. Dia tempat berangkat dan berlabuh dan memancarkan segala ilmu pengetahuan (multi disiplin ). Sedang manusia dalam kemakhlukannya berangkat dari tidak tahu, karena itu ia mempertanyakan dan belajar tentang segala sesuatu. 
Manusia harus belajar dan menggali pengetahuan dari wahyu Allah ( Al-Qur'an ) yang memuat dan menjelaskan segala hal ( QS. 16: 89) ). Kaiam suci dari Allah mengajarkan ilmu yang lahir dari rahimnya (Al-Qur'an ). Wahyu itu mengajarkan risaiah nubuwwah (prophetic knowledge ), ilmu yang bersifat membahagiakan, kepemurahan, dan kerahiman.

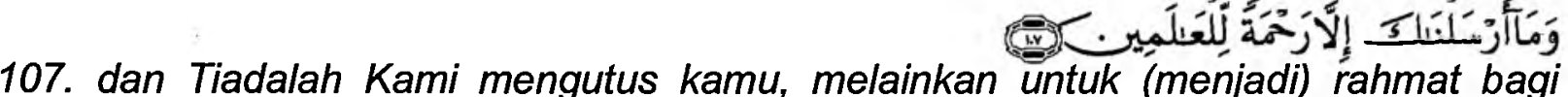
semesta alam. QS. Al-Ambiya' 21: 107

Ayat di atas mengandung keistimewaan yang diberikan kepada Nabi Pungkasan ,Muhammad SAW., sebagaimana keistimewaan juga diberikan kepada Nab-nabi sebelumnya. Meminjam istilah yang digunakan oleh seorang mufassir Indonesia, Qureish Shihab, keistimewaan itu adalah kepribadian beliau. (Quraish Shihab, 2009:134 )

Quraish Shihab menjelaskan bahwa Rasul SAW adalah rahmat, yakni sosok dan kepribadian beliau adalah rahmat yang dianugerahkan Allah SWT kepada beliau. Dalam kontekstualisasi dengan dunia pendidikan, Nabi SAW mengakui karunia dari Allah SWT: addabani rabbi fa ahsana ta'diibi.

Artinya: "Aku dididik oleh Tuhan-ku, maka sungguh baik hasil pendidikan-Nya." HR. Ibnu 'Asakir.

Quraish Shihab menambahkan: kepribadian beliau adalah apa yang diperoleh dirinya dibentuk sehingga bukan hanya pengetahuan yang Allah limpahkan kepada beliau melalui wahyu-wahyu -Nya, tetapi juga kalbu beliau disinari, bahkan totalitas wujud beliau merupakan rahmat bagi seluruh alam.

Disini dikemukakan seluruh pesan Quraish Shihab, beliau berujar bahwa : "pembentukan kepribadian Nabi Muhammad SAW sehingga menjadikan sikap, ucapan, perbuatan, bahkan seluruh totalitas beliau adalah rahmat bertujuan mempersamakan totalitas beliau dengan ajaran yang beliau sampaikan, karena ajaran beliau pun adalah rahmat menyeluruh dan ,dengan demikian, menyatu ajaran dan penyampai ajaran, menyatu risalah dan rasul, dan karena itu pula Rasul SAW adalah penjelmaan konkrit dari akhlak al-Qur'an sebagaimana dilukiskan oleh 'Aisyah ra. (HR. Ahmad bin Hambal). (Quraish Shihab, 2009: 134 )

Apa yang dikemukakan beliau tentu terdapat hikmah dan pelajaran menuju rethinking atau reinventing UII. Sejarahnya telah memberikan sebuah pelajaran dari salah satu asset perjuangan umat yang monumental. Bagaimanapunjuga ia telah meletakkan gerakan intelektual muslim, para cendikiawan muslim dan para ulama untuk terus membangun 'harakah islamiyah ilmiyah' yang tak dapat tidak harus dipagut erat.

Para penerus dan pelangsung amanat ini (mandate), mengharuskan tetap memegang 'apinya' (the spirit of tauhid) yang meratakan jalan bagi kelangsungan institusi ini melesat ke depan dengan penuh percaya diri (istiqamah) dan menghidupkan ruh peradaban Islam.

Sejalan dengan sosok Muhammad SAW beserta ajaran yang dibawa serta adalah sebagai kerahmatan bagi alam semesta. Apa yang termuat di dalam visi UII ' rahmatan lil'alamin' diaplikasikan dalam sebuah system pendidikan tinggi / universitas yang mengandung kerahmatan.

Sistem pendidikan universitas berbasis kerahmatan sebagai konsekwensi logis yang membukakan corak dan model pendidikan Islam di masa depan (to cope with future) dihadapkan pada isu global lingkungan hidup dan HAM.

Sebuah institusi pendidikan Islam yang segenap ilmu yang ditawarkan membawa kerahmatan yang meiiputi semua aktifitas akademikanya. Dr.Farid Wajdi, seorang ulama yang 
murabbi dari Mesir, membedah makna rahmah sebagai kelembutan hati yang melahirkan kasih sayang dan kebaikan dunia dan seluruh isinya dan seluruh alam semesta ada karena kasih sayang dan kebaikan Allah, karena itu Dia mengutus Muhammad SAW (menurunkan Islam) untuk menuntun manusia agar mampu menjadi khalifah (wakil penguasa) di bumi. Di samping itu di maksudkan agar status manusia tetap akan menjadi semulia-mulia dan sebaikbaik makhluk, tetap dapat dipertahankan.(Suyoto dkk, 1991: 9-10)

Bagi UII, pesan di atas telah dituangkan dan nampak jelas dalam rumusan misinya, yakni: Menegakkan Wahyu llahi dan Sunnah Nabi sebagai sumber kebenaran abadi yang membawa rahmat bagi alam semesta melalui pengembangan dan penyebaran ilmu pengetahuan, teknologi , budaya, sastra, dan seni yang berjiwa Islam, dalam rangka membentuk cendikiawan muslim dan pemimpin bangsa yang bertakwa, berakhlak mulia, berilmu amaliyah dan beramal ilmiyah, yang memiliki keunggulan dalam keislaman, keilmuan, kepemimpinan, keahlian kemandirian, dan profesionalisme. 8 (Agenda UII: 2013 )

Dalam misi di atas diperoleh gambaran aktualisasi Islam dan substansinya yang berfungsi sebagai petunjuk (pengarah-guiding principle), imam (pemimpin), cahaya obor penerang, rahmah (nikmat, kemakmuran, dan kesejahteraan, dan kasih sayang), serta syifa' (penawar dari gangguan fisik, mental dan social). Disini rahmatan lil'alamin merupakan tujuan/ sasaran akhir dari seluruh rangkaian kesatuan sistem ajaran Islam di UII. Dengan kata lain ia menjadi pewaris cita-cita Islam dan misi kerisalatan Nabi Muhammad SAW.

Perkembangan model pendidikan al-jaami-ah ( penghimpun segala ilmu ) dan mentranfer ilmu (transfer of knowledge) melalui lembaga pendidikan tinggi tidaklah berlangsung linier. Universitas sebagai sebuah institusi pendidikan adab (ta'dib), namun dalam prakteknya yang lebih mengedepan adalah pengajaran (tadris-studi) serta pendidikan (tarbiyah-education).

Institusi universitas ini di masa lalu pernah mengambil konsep pengislaman pengetahuan (Islamization of knowledge) untuk menghilangkan dikhotomi pendidikan. Dari segi peristilahan, sarjana muslim yang memperkenalkan istilah ini adalah Isma'il $R$. al-Faruqi dalam bukunya Islamization of knowledge: General Principles and Workplan dan Syed Naquib Al-atas dalam bukunya The Dewesternisation of knowledge. (A'bdullah Ali, 1998: 64 )

Tak ayal bagi UII ada keberpihakan sebuah sistem pendidikan/ pengajaran Islam yang seutuhnya serta komprehensip. Islamisasi pengetahuan haruslah membuka akses khazanah keilmuan dari mana saja.

Di sebelah UII lebih tekun menemukan nuansa-nuansa pendidikan abad ke $X X 1$ dengan tetap berpegang teguh pada kepustakaan utama pada Qur'an sebagai referensi atau sebuah buku induk pengetahuan saintifik yang segala ilmu (sains) merujuk kepadanya.

Universitas ini mencoba meluncurkan sebuah pendidikan yang utuh. la mengolah sisi kognisi (intelektual), sisi emosi (akhlak dan kepribadian) serta psiko motorik (perilaku). Ketiganya dimaksudkan terbentuknya perilaku sebagai pelopor (ing ngarso sung tulada), berhimmah/ berkemauan tinggi (ing madio mangun karso), dan pemberi motivasi/ motivator (tut wuri handayani).

Suatu proses pendidikan/ perkuliahan yang inovatif kerkelanjutan/ berkesinambungan menuju terbentuknya sosok cendikiawan yang hatinya terpaut dengan masjid (rajulun mu'allaqun bil masajid-nilai transendent) sebagai catur pusat pendidikan guna meraih insan ulul albab. Dalam Islam Nabi Muhammad SAW adalah pembawa risalah dan Al-Qur'an adalah kitab yang berisi pesan ajaran yang lengkap.

Meminjam istilah Ary Ginanjar Agustian, manusia digerakkan dalam segi pisik dan kecerdasan intelektualnya (cipta, analisa, logika dan rasio) terbimbing oleh 5 langkah bersumber Rukun Islam. Sisi kecerdasan emosi, yakni kemampuan mendengar suara hati 
sebagai sumber informasi, misalnya: komitmen, loyalitas, dan kepekaan yang dibentuk oleh 6 prinsip yang bersumber dari nilai Rukun Iman. (Ary Ginanjar Agustian, 2001:68)

Sementara kecerdasan spiritual berisi suara hati llahiyah (fithrah) bersumber dari percikan Asmaul Husna yang bersifat Universal. Segi ini bisa memberi kemampuan makna puncak spiritual (ultimate meaning), misalnya: spiritualisasi pekerjaan. Seiuruh gerakan bertawaf mengelilingi titik Tuhan (God Spot), (Ary Ginanjar Agustian, 2001: 284) dan UII menerjemahkannya fokus menuju titik Tauhid yang menjadi landasan hidup dalam pandangan hidup muslim. (M. Teguh, 2003: 1)

UII sebagai wadah proses pendidikan dan pengajaran tinggi hendaknya dilakukan pendinamisasian ilmu, iman dan amal. Universitas ini dikenal melahirkan intelek yang ulama dan ulama yang intelek, berilmu yang amaliyah dan beramal yang bertumpu secara ilmiyah. Hasil akhirnya akan tampil alumni /sosok muslim yang berdedikasi tinggi.

Dalam perspektip ini, dapat ditarik pembeda antara sistem pendidikan di UII dengan sistem Barat modern, yakni penghargaan tinggi pada iman dan kesalehan sebagai salah satu tujuan-tujuan asasinya. Jadi bukan hanya bertumpu pada asas manfaat (naf'iyyah-utilitas). Maksudnya sistem pendidikan Islam tidak boleh hanya mengandung perencanaan karir sebagai metodologi dasarnya. Lebih jauh tujuan dari pendidikan muslim adalah terbentuk nya seorang muslim sejati. . DR. Syed Sajjad Husein dkk1986: 66 ).

Lebih jauh, sebuah Model pendidikan tinggi Islam yang mengacu pada perencanaan Islamisasi dan pengintegrasian pendidikan dapat diambil contoh dari Universitas Internasional Islam Malaysia. Tujuan dari Universitas tersebut dapat disebutkan disini sbb:

1. The University follows Islamic tradition ing persuing knowledge and in this context it is important to consider the contribution of the early Muslim scholars and thinkers that began with the teachings of our Holy Prophet Muhammad (P.B.U. H). Thus the primacy of Islam in all fields of knowledge is reestablished.

2. It emphasizes in the Islamic concept of learning in which the seeking of knowledge is considered as an act of ibadah. The search for knowledge and the pursuit of scientific inquiry are done as inspired by the teachings of Holy Qur'an.

3. Knowledge is propagated in the spirit of Tawhid and submission to Allah. The obyective is to produce commited Muslim professionals who are conscious of their responsibilities as obedient servants of Allah and His khalifah on earth.

4. To enable the Muslim ummah to venture into a wide choice of higher education and excel in all form of academic achievement. (Aris Othman:2001:1)

Apabila dibandingkan antara tujuan (visi dan misi) UII Indonesia dengan UlI Malaysia, secara substansiai sama. Namun UII Malaysia lebih tajam, yakni Islam menjadi prinsip pemandu pembelajaran dan pengajaran dan dalam bidang riset akademik serta programprogram pengembangan mahasiswa menuju terbentuknya mahasiwa yang berkepribadian utuh (integrated personality). Last but not least, keduanya saling mengisi.

Sebuah catatan tentang kepribadian yang utuh dimaksudkan berkeahlian (professional) di bidangnya seperti pakar ilmu kedokteran, pakar teknik, pakar ekonomi, pakar ilmu social, pejabat agama. Tetapi mereka juga menjadi muslim yang berkomitmen dengan dan berdedikasi kepada umat. Tujuan universitas adalah integritasisasi, islamisasi, internasionalisasi serta keunggulan yang komprehensip (IIICE )

\section{RIHLAH ILMIYAH}


Kampus UII dilihat dari perjalanan sejarahnya bagaikan 'rihlah ilmiyah' dengan semangat pelawat muslim terkenal dalam bukunya 'rihlah Ibnu Bathuthah'. Yaitu sebuah memoir Perjalanan keliling Dunia di abad pertengahan. Penulisnya bernama Muhammad bin Abdullah bin Bathuthah, nama aslinya Muhammad bin Abdullah bin Muhammad bin Ibrahim Al-Lawati At-Tanji, lahir di kota Tanjier, tahun 1304 M Maroko. ( Ibnu Bathuthah, 2009: x )

Menurut penerbit (Pustaka Al-Kautsar ) Ibnu Bathuthah piawai dalam penyebutan tokohtokoh, raja-raja, tempat kejadian, cerita sosial yang populer di masa itu, keadaan dan kejadiankejadian. Dia pandai menceritakan situasi kehidupan zaman Islam, dengan segala kelebihan dan kekurangan. Ibnu Bathuthah tetap memahami aspek-aspek ajaran Islam, sehingga setiap ceritanya dikorelasikan dengan ajaran-ajaran Islam ( meskipun bercorak kesufian ).

Sejujurnya, Rihlah Ibnu Bathuthah, seperti sebuah mozaik kebudayaan Islami yang disampaikan oleh Ibnu Bathuthah agar terwujud di bumi. Bahkan, tanpa disadari, Ibnu Bathuthah telah menunjukkan pentingnya kesatuan Wilayah Islam, yang berada di wilayah Arab, Syam, Afrika, India, maupun asia Tenggara.11 Al-Qur'an memberikan semangat perlawatan semacam yang dilakukan Ibnu Mathuthah, yakni lawatan untuk menuntut ilmu sebagai berikut:

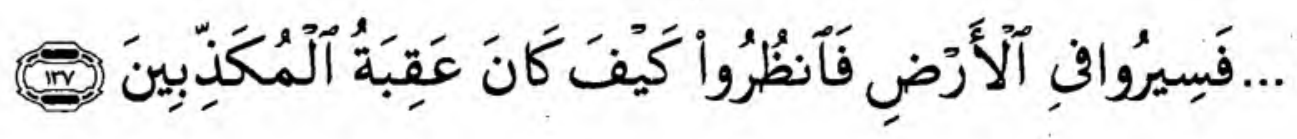

karena itu berjaianiah kamu di muka bumi dan perhatikaniah bagaimana akibat orangorang yang mendustakan (agama ailah ). QS. Ali Imran 3: 137

Ibnu Bathuthah dengan memoirnya dipandang sebagai magnum opus/ karia utama , karena dijadikan rujukan oleh para sejarahwan dari berbagai kalangan, timur dan barat. Ibnu Bathuthah adalah contoh yang sedikit dari kaum muslimin yang menangkap semangat perjalanan suci ( Hijrah ) dari Al-Musthafa.

Hijrah merefeksikan sebuah amal saleh yang mendatangkan rida Allah SWT, karena orang yang berhijrah melakukan pengorbanan besar di jalan Allah SWT. Hijrah telah memperkokoh iman para sahabat dan telah memberikan warna istimewa kepada kaum muslim dan Islam. Demikian pendapat Muhammad Fethullah Gulen, seorang ulama kharismatis \& Inspiratif bagi Dunia Islam dari Turki.

Beliau menambahkan, bahwa perjalanan suci (hijrah) saat ini, dilihat dari sisi dakwah, menjadi lebih penting daripada sebelumnya. Sesuai dengan kaidah: "amal perbuatan itu dengan niat, dan setiap orang mendapatkan apa yang diniatkannya."

Semangat ini pula yang hidup dan diusung oleh UII mengirimkan dosen-dosennya ke barbagai universitas di dunia baik ke Barat maupun ke Timur; Disamping keberbagai universitas domestlk di Indonesia dalam berbagai disiplin keilmuan. Berbahagialah Ull sekarang telah memiliki doktor lebih dari seratus jumlahnya dalam berbagai disiplin keilmuan.

Belum lagi para guru besar yang memberi warna serta arah perjalanan ilmu. Hal ini menggambarkan bernyalanya budaya akademik, budaya iqra' dan ta'allum di universitas, sebaiknya para guru besar dan para doktor lintas ilmu tersebut merupakan sebuah konsorsium ilmu (al-ittihad al-ilmy) untuk memacu kemajuan ilmu.

Bukan hanya itu, UII adalah juga sebuah institusi dakwah melalui pendidikan yang dapat dikategorikan sebagai dakwah khusus di kampus dalam wajah dakwah bil hal, bil maqal, baik kepada umat muslim untuk meningkatkan mutu dan melahirkan keluaran (out put) yang berbobot mubtadi (innovator) dan bukan sekedar mubdi'/ pengikut, dan sama sekali bukan seorang dengan budaya 'copy and paste'. Mereka senantiasa terbaharukan imannya dan ilmunya dan, teraplikasi bagi kepentingan masyarakat banyak. 
Namun juga dakwah kepada mereka yang mu'allaf dan non muslim agar tergerak berkenalan dan hatinya mencintai Islam. Sehingga mereka termasuk komunitas yang terselamatkan, beroleh nilai tambah / terberkahi (added value ) dan terahmati. Dalam era informasi ( mass information ) UII itu adalah obor penerang masyarakat ( the torch of society ) yang ilmunya memberikan pencerahan kepada umat menuju masyarakat madani.

UII bukan sebuah menara gading yang elitis, arogan, eksklusif serta mabuk sanjungan. Sebaliknya di dalam kampus ini nampak suasana kondusif ketawadhuan (kerendah hatian), kebersahajaan, dan semangat ar-rasikhun fil 'ilm orang-orang(ulama) yang mendalam ilmunya yang mencuatkan hati emas (ketulusan).

Lain daripada itu, bukankah sekarang ini kaum muslimin sedunia dipersatukan secara politik dalam Organisasi Konferensi Islam (OKI) dan Ar-Rabithah al-Alam Al-Islam dalam bidang agama, pendidikan, ekonomi dan kebudayaan. Disini dapat diajukan sebuah impian dimanakah peran UII sebagai 'the International Islamic University'?

\section{UII PEMANTIK PERADABAN}

Kalau dalam sejarah Islam, didapati sebuah universitas Andalusia-Spanyol Islam yang membawa kota Cordoba, menjadi kota termaju di sebelah barat Eropa. Zaman emas kota Cordoba terjadi di masa Dinasti Umayah 756-1031 M. ( Zainal Abidin Ahmad,1977: 95 )

Universitas ini telah menjadi pusat kemajuan dan pencerahan di seluruh dunia, khususnya menjadi awal Eropa menyingkap abad kegelapannya (the dark age). la telah mnelahirkan para pujangga muslim, seperti lbnu Sina (Avicena) Ibnu Rusd (Arrus), Ibnu Khaldun, Ibnu Bajja (Avenpace) dan masih banyak lagi.

Adalah di masa kekuasaan Fathimiyah di Mesir Afrika Utara. Fathimiyah menjadi lambang kemajuan di Mesir. la mendirikan kota Kairo dan sekolah tinggi Islam yang termashur yaitu Al-Azhar university yang telah berusia 1000 tahun lebih. Pada akhirnya UII akan menggenapinya sebagai universitas berkelas dunia (WCU), dikhidmatkan pula untuk dunia Islam guna mewujudkan peradaban di masa depan.

UII harus menorehkan dirinya dan pro aktif memulai membangun dirinya sebagai salah satu kiblat universitas Islam di Asia Tenggara sehingga akan terbentuk kekuatan peradaban Islam kembali di Timur. UII tidak mustahil mampu memunculkan dirinya sebagai salah satu pemantik peradaban Islam (hadlarah Islam) tersebut .

Universitas ini terus melakukan upaya-upaya untuk berbenah diri (institutional empowerment) dengan menjauhkan dirinya dari pandangan bahwa manfaat sebagai tolok ukur segala perbuatan. Karena hal demikian menjadi potret dasar sistem hadlarah Barat yang merisaukan. Hadlarah kata Slamet Sukirnanto, adalah paham tentang kehidupan, tentang pandangan hidup dan pandangan dunia (weltanchaung-mu'amalah duniawiyah). ]

Ada kelangsungan mengalir dalam kampus ini (kampung) yang tegak pada pijakan atas dasar iman kepada Allah SWT., seperti yang tertuang dalam trilogi Islam. Dalam kampus ini berlangsung sebuah kehidupan yang diawali dengan kebenaran akidah, Para penghuninya melangsungkan segala akitifitanya secara etik Islam yang menggumpal dalam etos kerja ilmiyah, menampakkan kebaikan atau kebajikan (insan).

Apa yang dicanangkan oleh UII sebagai kebijakan mutu, adalah 'on the right tract' dan , merupakan keniscayaan untuk mewujudkan sebuah universitas Islam yang kualitatif, kreatif dan inspiratif yang terpancar dari rumusan mutu yang dibuatnya : 
Universitas Islam Indonesia sebagai universitas yang memiliki keunggulan pendidikan dan penelitian di tingkat ASEAN, menghasilkan lulusan berdaya saing tinggi, menguasai serta menghasilkan ilmu dan nilai keislaman. (Agenda UII, 2013)

UII sebagai penyedia sumber daya insan melalui proses perkuliahan yang berbasis kerahmatan, sangat menentukan. Menurut Slamet Sukirnanto, seorang budayawan, sumber daya insan secara kualitatip harus memiliki kemampuan keahlian dan sikap modern, seperti:

(a ). Bekerja secara mekanis, karena bekerja dengan mesin-mesin;

(b ). Bekerja secara rasional, karena diperlukan dan efisiensi;

(c). Bekerja spesialisasi , menekuni bidang-bidang khusus yang menjadi keahliannya;

(d). Bekerja secara otomatis, menghadapi mekanisme alat produksi yang serba otomatis.

Bagi beliau hal demikian melambangkan kecenderungan materi, pragmatisme, yang menyebabkan sekularisme tambah merajalela. Cara kita, kata beliau, memahami pengertian kemajuan dan modernism, yang dihadapkan dengan landasan -landasan dan pandangan hidup cara Islam. ( Slamet Sukirnanto, 1993:12 )

Tata cara hidup sepanjang tuntunan Islam (the Islamic way of life) dalam corak keseimbangan (tawazun) adalah sejalan dan memberi warna yang anggun di UII. Keindahan dan keunggulan ajaran Islam menjadi pilihan maju dan membahagiakan.

Peta lokasi kampus yang luas meliputi lebih dari 25 ha dengan unit-unit bangunan yang banyak serta lingkungan yang rindang dengan masjid 'Ulul Albab' sebagai pusat kampusnya. Begitu juga jaringan multi media milik UII, muara pengaplikasian teknologi komunikasi pendidikan, diusahakan membantu proses perkuliahan dan peningkatan sivitas akademika sebagai jalan memanfaatkan secara optimal sumber-sumber belajar melalui fungsi pengembangan dan pengelolaan.

Hal ini mencakup di tingkat universitas, fakultas, dan jurusan. Tentu saja dengan tersedianya SDM yang meliputi guru besar, doctor, dosen, para peneliti dan lain-lainnya. Mereka adalah para pengajar yang baik, memiliki status dan peranan yang istimewa serta tanggung jawab. Yang terpenting mereka adalah pengajar yang beriman yang mengimbangi tanggung jawab mereka kepada masyarakat dengan tanggung jawab kepada Tuhan. (Abdul Ghafur, 1993: 3 )

Tersedianya dana dan usaha yang produktif yang mendukung terselenggaranya proses pembelajaran dan pengajaran yang multi disipliner sangat mernggembirakan dan patut disyukuri. Tidak dilupakan adanya dan tercapainya sejumlah prestasi di dalam dan an di luar negeri. Tetapi perlu disusul sebuah evaluasi pengendalian mutu untuk ditarik dari awal berdirinya universitas untuk lebih maju melaju ke depan dengan menggunakan teori reinventing wheel.

Sebuah otokritik melalui suara seorang dosen, Syaifudin Ali Ahmad, dosen FK UII tertumpang harapan dalam songsong Milad UII ke-70; supaya disertai semangat yang menunjukkan kematangan bukan justru kemunduran layaknya orang lanjut usia atau geriatric yang terkena sindrom B komplek, blawur, bruwet, beser, bungkuk, budeg, dan bingung.

Beliau menambahkan upaya pencegahan dari masalah / dampak usia lanjut sebagai' a series of I's: immobility (imobilisasi), instability (instabilitas dan jatuh) incontinence (inkontinensia), intellectual impairment (gangguan intelektual), infection (infeksi), impairment of vision and hearing (gangguan penglihatan dan pendengaran), Isolation (depresi), inanition (malnutrisi), insomnia (gangguan tidur), immune deficiency (menurunnya kekebalan tubuh). (UII News: 2013: 10. ) 
Alangkah fatalnya apabila hal-hal tersebut menimpa UII. Gerakan tandhif (bebersih diri) dari gangguan atau ancaman secara mental, moral dan social hendaknya terus dikobarkan sebagai manifestasi tradisi Islam dengan berthaharah.

Tidak hanya thaharah dalam setiap memulai peribadahan Islam yang menjadi keharusan. Namun secara konseptual dalam perspektip peradaban, dari sisi falsafah (the filosophy of meaning) melahirkan para muthahhar (para pencerah) peradaban.

UII perlu belajar dari Ibrahim as sang Nabi Khalilullah, yang gigih belajar dan berjuang mencari jawaban dari rahasia hidup. Beliau mencoba memungsikan nalarnya untuk menyingkap apa yang dibalik suatu kehidupan, dan terus melesat kepada pertanyaan besar (big question). Emha Ainun Najib, seorang budayawan muslim yang dikenal sebagai kyai Kanjeng, mengangkat pencarian Tuhan dari Ibrahim as dalam puisinya:

Sesudah berulang kali bangun dan terbanting

Merenung dan mencarilah hamba sebagai Ibrahim

Menatap laut, bulan, bintang , dan matahari

Sampai gamblang bagi hamba ... Allah yang sejati

Jadilah hamba pemuda pengangkat kapak

Menghancurkan berhala sampai luluh lantak

Hamba lawan jika pun Fir'aun sepuluh jumlahnya

Karena api sejuk membungkus badan hamba. (Miftah Fauzi Rahmat,2011: 105 )

Semangat Emha dengan kapak menghadapi sepuluh Fir'aun, yang sudah barang tentu UII dengan semangat sama memegang pena perlu mengambil langkah yang benar (a giant leap). Sekali lagi Muhammad Fethullah Guien seakan mengirim pesan (message) untuk UII , beliau menganjurkan :

untuk membersihkan sains yang ada saat ini dari berbagai kebekuan dan kesia-siaan.Ini akan membantu untuk memahami persoalan berbagai hal yang menjadi perhatian ilmu pengetahuan, di samping juga untuk mengantarkan manusia untuk bisa melakukan apa yang ada dalam benak dan pikirannya sehingga dapat menyaksikan berbagai hal yang didapatkan oleh perasaan dan kalbunya secara rutin.Kalau ini terjadi, sang cendikiawan akan berbalik menjadi lesan yang fasih dan kalbu yang bisa membaca alam yang terhampar luas dihadapannya sebagai buku yang terbuka, baris demi baris. Karena itulah perintah pertama dalam Al-Qur'an adalah"Bacalah!" ( M.Fethullah Gulen --)

\section{KESIMPULAN}

Universitas Islam Indonesia keberadaannya merupakan bagian dari sejarah umat Islam Indonesia, konsisten ( beristiqamah ) dalam pengabdian penyebaran ilmu dan Islam komprehensip seutuhnya. Sedangkan Visi dan Misi Ull penjabarannya merupakan suatu 'sine qua non' yang bermuara pada sistem pendidikan Islam yang berbasis kerahmatan.

Makna cendikiawan muslim mencakup: inteligensia Muslim, insan ulul albab, muslim yang berdikasi tinggi, para muthahhar ( penerah peradaban ), ar-rasikhun fil'ilm -orang/ ulama yang mendalam ilmunya. Peran UII sebagai pemantik peradaban mengharuskan dirinya sebagai 'center of excellence' yang berperan menjadi International Islamic university di Asean, penerus semangat keilmuan Universitas Islam Andalusia -Spanyol Islam, bersifat sublimatip dan sebagai mandate /amanah keilmuan dalam Islam. 
UNISIA, Vol. XXXV No. 78 Januari 2013

\section{DAFTAR PUSTAKA}

Agustian, Ary Ginanjar, 2001. E.S.Q.-Emotional Spiritual Quotient- berdasarkan 6 rukun Iman dan 5 rukun Islam, Jakarta, Arga Wijaya Persada.

Ahmad, Zainal Abidin, 1978. Sejarah Politik Islam VI, Jakarta, Penerbit Bulan Bintang

Ali, Abdullah \& Sudarno Shobron, 1998, Studi Islam 2, Surakarta: Lembaga Studi IslamUniversitas Muhammadiyah

Bathuthah Muhammad bin Abdullah,2012. Rihlah Ibnu Bathuthah, Jakarta: Pustaka AlKautsar.

Gulen, Fethullah M, 2011. Islam Rahmatanlil'alamin, Jakarta: Penerbit Republika,

Ghafur Abdul, 1993. Pengembangan Multi Media Sebagai Model pendekatanDakwah Islam Abadke XX1,1413, Makalah Pengajian Ramadhan, Yogyakarta, BPK. PP. Muhammadiyah.

Husein, S. Sajad \& SA. Asyraf , 1986M-1407 H. Krisis Pendidikan Islam-Terjemahan, Bandung, Penerbit Risalah.

Latif Yudi, 2005. Intelegensia Muslim dan Kuasa: Genealogi Intelegensia Muslim Indonesia Abad ke 20, Bandung, PT. Mizan.

Mahfud MD Moh, 1997. Spiritualitas Al-qur'an dalam kearifan umat,Yogyakarta,UII Press.

Otsman, Mohammed Aris, 2001. Planning for Islamization and Integration-IIUM Experience, materi lokakarya Pengembangan Pendidikan Tinggi Hukum berwawasan Syari'ah, Yogyakarta, Fakultas Hukum \& STHI di Lingkungan Perguruan Tinggi Muhammadiyah.

Rahmat Miftah Fauzi, 2011. the prophetic Wisdom-Kisah-kisah Kearifan Para Nabi-nabi, Bandung, Penerbit Mizania.

Shihab, M Quraish, 2009. Tafsir AL MISBAH-vol 14, Jakarta, Lentera Hati , Tafsir AL MISBAH-vol 8, Jakarta, Lentera Hati.

SSuyoto dkk, 1998. Studi Islam 2, Malang, PDKIM- Universitas Muhammadiyah.

SSukirnanto Slamet, 1993. Peluang-peluang Dakwah Islam Dalam Transformasi budaya di Era Industrialisasi, Yogyakarta, 1413. Makalah Pengajian Ramadhan, Yogyakarta, BPK. PP. Muhammadiyah.

Teguh, Muhammad dkk, 2013 Menuju kemantapan Tauhid Dengan Ibadah dan akhlakul Karimah,2013, Yogyakarta,UII. 